\title{
Menentukan Nilai Eigen Tak Dominan Suatu Matriks Semi Definit dan Indefinit Menggunakan Metode Kuasa Invers dengan Shift
}

\author{
Arif Bijaksana ${ }^{1}$, Irma Suryani ${ }^{2}$ \\ Jurusan Matematika Terapan, Fakultas Sains dan Teknologi, UIN Sultan Syarif Kasim Riau \\ Jl. HR. Soebrantas No. 155 Simpang Baru, Panam, Pekanbaru, 28293 \\ Email: abijaksanaz@gmail.com, irmayath@yahoo.co.id
}

\begin{abstract}
ABSTRAK
Makalah ini menggunakan metode kuasa invers dengan shift. Metode kuasa invers dengan shift merupakan suatu metode untuk mengaproksimasi nilai eigen tak dominan dan vektor eigennya dari suatu matriks. Nilai eigen dikatakan tak dominan jika ada salah satu nilai mutlak terkecil dari nilai mutlak eigen lainnya. Hasil yang diperoleh yaitu nilai eigen tak dominan dari matriks semi definit adalah 0 . Pada matriks indefinit diperoleh nilai eigen tak dominan adalah $-0,5828$. Nilai shift sangat bepengaruh terhadap nilai eigen tak dominan yang dihasilkan. Semakin nilai shift mendekati nilai eigen tak dominan, maka hampiran nilai eigen tak dominan semakin mendekati nilai eigen tak dominan yang eksak. Sehingga lebih baik jika nilai shift yang diperkirakan sangat mendekati nilai eigen tak dominan.
\end{abstract}

Kata Kunci: Matriks Semi Definit, Matriks Indefinit, Metode Kuasa Invers dengan Shift, Nilai Eigen Tak Dominan, Teorema Gerschgorin

\begin{abstract}
In this paper used is the shifted inverse power method. The shifted inverse power method a method for approximation not dominant eigenvalues and vectoreigen of a matrix. Eigenvalues said to be not dominant if there is one of the smallest absolute value of the absolute value of the other eigenvalues. The result a not dominant eigenvalues of matrix semi definite is 0 . The not dominant eigen values a matrix indefinite is $-0,5828$. Shift value very affect towards not dominant eigenvalues generated. The more the value of the shift approach was not dominant eigenvalues, then the approximation is not dominant eigenvalues closer not dominant eigenvalues exact. So it is better if the value of the expected shift very close to not dominant eigenvalues.
\end{abstract}

Keywords: Not Dominant Eigenvalues, Semi Definite Matrix, Indefinite Matrix, The Shifted Inverse Power Method, Gerschgorin Theorem.

\section{Pendahuluan}

Nilai eigen dan vektor eigen yang bersesuaian merupakan salah satu bagian dari cabang ilmu matematika yaitu aljabar linear. Pembahasan nilai eigen dan vektor eigen memegang peranan sangat penting dalam pengembangan dunia keilmuan. Nilai eigen sebuah matriks dapat dicari dengan memecahkan persamaan karakteristiknya. Penyelesaian persamaan karakteristik ini akan menghasilkan nilai eigen dominan dengan vektor eigen yang bersesuaian dan nilai eigen tak dominan dengan vektor eigen yang bersesuaian. Nilai eigen dikatakan dominan jika ada salah satu nilai eigen mutlak yang paling besar dibandingkan dengan nilai mutlak nilai-nilai eigen lainnya. Sebaliknya nilai eigen dikatakan tak dominan jika ada salah satu nilai eigen mutlak yang paling kecil dibandingkan dengan nilai mutlak nilai-nilai eigen lainnya. Di dalam pengaproksimasian nilai eigen dominan digunakan metode kuasa, sedangkan untuk nilai eigen tak dominan digunakan metode kuasa invers.

Suatu permasalahan nilai eigen dan vektor eigen, terlebih dahulu dicari adalah nilai eigennya setelah itu baru dicari vektor eigennya. Sedangkan pada metode pangkat invers dalam mencari nilai eigennya, yaitu dengan menentukan vektor eigennya terlebih dahulu setelah itu baru dicari nilai eigennya. Selain metode kuasa invers, nilai eigen tak dominan dapat ditentukan dengan menggunakan metode kuasa invers shift. 
Besarnya nilai shift yang akan diperoleh menggunakan penerapan Teorema Gerschgorin. Nilai shift ini merupakan nilai pendekatan dari nilai eigen tak dominan. Salah satu cara menentukan nilai eigen tak dominan apabila diaproksimasi terhadap vektor eigen tak dominan adalah menggunakan Kuesien Rayleigh.

\section{Metode Penelitian}

\section{Matriks Definit}

Definisi 1 : Matriks adalah himpunan elemen-elemen yang membentuk susunan baris dan kolom.

Sebuah matriks simetrik $A$ dan bentuk kuadratik $x^{T} A x$ disebut

1) Semi definit positif jika $x^{T} A x \geq 0$ untuk semua $x$.

2) Definit negatif jika $x^{T} A x<0$ untuk semua $x \neq 0$.

3) Semi definit negatif jika $x^{T} A x \leq 0$ untuk semua $x$.

4) Tidak definit (indefinit) jika $x^{T} A x$ memiliki nilai positif maupun nilai negatif.

\section{Nilai Eigen Tak Dominan}

Definisi 2 : Jika sebuah nilai eigen dari sebuah matriks $A$ adalah $\lambda_{1}, \lambda_{2}, \ldots . \lambda_{n}$ dan jika $\left|\lambda_{1}\right|<\left|\lambda_{2}\right|<$ $\left|\lambda_{n}\right|$, kemudian $\lambda_{1}$ disebut nilai eigen tak dominan dari $A$. Vektor eigen yang bersesuaian dengan nilai eigen tak dominan disebut vektor eigen tak dominan dari $A$.

\section{Bentuk Kuadrat}

Definisi 3 : Suatu bentuk kuadrat $f(x)=x^{T} A x$ disebut definit jika bentuk kuadrat tersebut hanya mempunyai tanda yang sama, dimana $x$ bervariasi atas semua vektor-vektor taknol dalam $R^{n}$. Bentuk tersebut definit positif jika $x^{T} A x>0$ untuk semua $x$ taknol dalam $R^{n}$ dan definit negatif jika $x^{T} A x<0$ untuk semua $x$ taknol dalam $R^{n}$. Bentuk kuadrat disebut indefinit jika mempunyai nilai-nilai dengan tanda yang berbeda. Jika $f(x)=x^{T} A x \geq 0$ dan memiliki nilai nol untuk suatu $x \neq 0$, maka $f(x)$ disebut semi definit positif. Jika $f(x)=x^{T} A x \leq 0$ dan memiliki nilai nol untuk suatu $x \neq 0$, maka $f(x)$ disebut semi definit negatif.

\section{Metode Kuasa Invers dengan Shift}

Metode ini secara perhitungan menggunakan suatu nilai pendekatan terhadap nilai eigen tak dominan dari matriks $A$ yang disebut dengan shift. Besarnya nilai shift akan diperoleh menggunakan Teorema Gerschgorin.

Salah satu cara menentukan nilai eigen tak dominan apabila aproksimasi terhadap vektor eigen tak dominan telah diketahui dengan menggunakan nilai bagi Rayleigh untuk suatu matriks simetrik $A$ yaitu: Teorema 1 : Jika $x$ adalah sebuah vektor eigen dari matriks $A$, dan bersesuaian dengan nilai eigen maka

$$
\lambda=\frac{\langle x, A x\rangle}{\langle x, x\rangle}
$$

Hasil bagi ini disebut Kuesien Rayleigh

Dimana:

$\lambda=$ nilai eigen tak dominan

$x=$ vektor eigen tak dominan

$A=$ matriks $n \times n$ 


\section{Hasil dan Pembahasan}

Bagian ini akan membahas tentang penggunaan metode kuasa invers dengan shift pada matriks semi definit positif, semi definit negatif, dan indefinit pada matriks yang berukuran $5 \times 5$.

Berikut ini akan diberikan contoh matriks berukuran $5 \times 5$,

$$
\text { Misalkan matriks } A=\left[\begin{array}{lllll}
a_{11} & a_{12} & a_{13} & a_{14} & a_{15} \\
a_{21} & a_{22} & a_{23} & a_{24} & a_{25} \\
a_{31} & a_{32} & a_{33} & a_{34} & a_{35} \\
a_{41} & a_{42} & a_{43} & a_{44} & a_{45} \\
a_{51} & a_{52} & a_{53} & a_{54} & a_{55}
\end{array}\right]
$$

Matriks simetrik $A$ dan bentuk kuadrat $x^{T} A x$ dikatakan semi definit positif jika $x^{T} A x \geq 0$.

$$
\left[\begin{array}{lllll}
x_{1} & x_{2} & x_{3} & x_{4} & x_{5}
\end{array}\right]\left[\begin{array}{lllll}
a_{11} & a_{12} & a_{13} & a_{14} & a_{15} \\
a_{21} & a_{22} & a_{23} & a_{24} & a_{25} \\
a_{31} & a_{32} & a_{33} & a_{34} & a_{35} \\
a_{41} & a_{42} & a_{43} & a_{44} & a_{45} \\
a_{51} & a_{52} & a_{53} & a_{54} & a_{55}
\end{array}\right]\left[\begin{array}{l}
x_{1} \\
x_{2} \\
x_{3} \\
x_{4} \\
x_{5}
\end{array}\right] \geq 0
$$

Matriks simetrik $A$ dan bentuk kuadrat $x^{T} A x$ dikatakan semi definit negatif jika $x^{T} A x \leq 0$.

$$
\left[\begin{array}{lllll}
x_{1} & x_{2} & x_{3} & x_{4} & x_{5}
\end{array}\right]\left[\begin{array}{lllll}
a_{11} & a_{12} & a_{13} & a_{14} & a_{15} \\
a_{21} & a_{22} & a_{23} & a_{24} & a_{25} \\
a_{31} & a_{32} & a_{33} & a_{34} & a_{35} \\
a_{41} & a_{42} & a_{43} & a_{44} & a_{45} \\
a_{51} & a_{52} & a_{53} & a_{54} & a_{55}
\end{array}\right]\left[\begin{array}{l}
x_{1} \\
x_{2} \\
x_{3} \\
x_{4} \\
x_{5}
\end{array}\right] \leq 0
$$

Matriks simetrik $A$ dan bentuk kuadrat $x^{T} A x$ dikatakan indefinit jika $x^{T} A x$ memiliki nilai positif maupun nilai negatif.

Selanjutnya, matriks semi definit dan indefinit yang diberikan akan ditentukan nilai eigen tak dominan dengan langkah-langkah sebagai berikut:

1. Diberikan sebarang matriks $A$ sebagai matriks simetrik semi definit dan indefinit.

2. Menentukan vektor hampiran awal $\left(X_{0}\right)$ dan menormalkannya

3. Menentukan nilai shift dengan menggunakan Teorema Gerschgorin.

4. Perhitungan dengan metode kuasa invers dengan shift dengan memberikan nilai shift-nya yaitu $(A-S I)=L U$

5. Tentukan matriks $L$ sebagai matriks segitiga bawah dan matriks $U$ sebagai matriks segitiga atas dari matriks $A$ untuk metode kuasa invers dengan shift.

6. Menyelesaikan $L Y=X$ dan $U Z=Y$

7. Menghitung $Z_{k}=\frac{Z}{\|Z\|}$

8. Mengalikan matriks $A Z_{k}$

9. Menghitung nilai eigen tak dominan dengan menggunakan $\lambda=\frac{\langle x, A x\rangle}{\langle x, x\rangle}$

10. Mengulangi langkah ke 6 dengan $Z=X_{0}$ sampai nilai eigen tak dominan yang ditentukan mendekati nilai eigen tak dominan dari matriks simetrik semi definit dan indefinit.

11. Berhenti jika $\lambda_{k}=\lambda_{k+1}$

Berikut ini diuraikan secara jelas bagaimana menentukan nilai eigen tak dominan suatu matriks dengan menggunakan metode kuasa invers.

\section{Matriks $5 \times 5$ Semi Definit Positif}

Diberikan sebarang matriks semi definit positif $5 \times 5$.

$$
A=\left[\begin{array}{ccccc}
1 & 1 & -1 & -2 & 2 \\
1 & 2 & 1 & -2 & 3 \\
-1 & 1 & 6 & 3 & 1 \\
-2 & -2 & 3 & 6 & -4 \\
2 & 3 & 1 & -4 & 7
\end{array}\right]
$$

Dengan vektor hampiran awal $\left[\begin{array}{l}-1 \\ -1 \\ -1 \\ -1 \\ -1\end{array}\right]$

Dengan menggunakan metode kuasa invers dengan shift untuk menentukan nilai eigen tak dominan dai matriks A 
1. Nomalisasi vektor hampiran awal menghasilkan

$$
X_{0}=\frac{1}{\sqrt{5}}\left[\begin{array}{l}
-1 \\
-1 \\
-1 \\
-1 \\
-1
\end{array}\right]=\left[\begin{array}{l}
-0,4772 \\
-0,4772 \\
-0,4772 \\
-0,4772 \\
-0,4772
\end{array}\right]
$$

2. Selanjutnya menentukan vektor eigen tak dominan dan nilai eigen tak dominan menggunakan metode kuasa invers dengan shift matriks A adalah menentukan nilai shift, matriks L dan matriks U. Menurut Teorema Gerschgorin daerah nilai eigen matriks A adalah

$$
\begin{aligned}
|\lambda-1| \leq|1|+|-1|+|-2|+|2|=6 & \\
|\lambda-2| \leq|1|+|1|+|-2|+|3|=7 & \\
|\lambda-6| \leq|-1|+|1|+|3|+|1|=6 & \quad|\lambda-7| \leq|2|+|3|+|1|+|-4|=10 \\
|\lambda-6| \leq|-2|+|-2|+|3|+|-4|=11 & \\
|\lambda-1| \leq 6 & \Leftrightarrow-6<\lambda-1<6 \\
& \Leftrightarrow-6+1<\lambda<6+1 \\
& \Leftrightarrow-5<\lambda<7 \\
|\lambda-2| \leq 7 & \Leftrightarrow-7<\lambda-2<7 \\
& \Leftrightarrow-7+2<\lambda<7+2 \\
& \Leftrightarrow-5<\lambda<9 \\
|\lambda-6| \leq 6 & \Leftrightarrow-6<\lambda-6<6 \\
& \Leftrightarrow-6+6<\lambda<6+6 \\
& \Leftrightarrow 0<\lambda<12 \\
|\lambda-6| \leq 11 & \Leftrightarrow-11<\lambda-6<11 \\
& \Leftrightarrow-11+6<\lambda<11+6 \\
& \Leftrightarrow-5<\lambda<17 \\
& \Leftrightarrow-10+7<\lambda<10+7 \\
|\lambda-7| \leq 10 & \Leftrightarrow-10<\lambda-7<10
\end{aligned}
$$

Jadi daerah nilai eigennya $0<\lambda<7$. Dimisalkan diambil nilai shift $s=0,1$ maka $A$ menjadi:

$$
\begin{aligned}
& (A-s I)=\left[\begin{array}{ccccc}
1 & 1 & -1 & -2 & 2 \\
1 & 2 & 1 & -2 & 3 \\
-1 & 1 & 6 & 3 & 1 \\
-2 & -2 & 3 & 6 & -4 \\
2 & 3 & 1 & -4 & 7
\end{array}\right]-\left[\begin{array}{ccccc}
0,1 & 0 & 0 & 0 & 0 \\
0 & 0,1 & 0 & 0 & 0 \\
0 & 0 & 0,1 & 0 & 0 \\
0 & 0 & 0 & 0,1 & 0 \\
0 & 0 & 0 & 0 & 0,1
\end{array}\right] \\
& =\left[\begin{array}{ccccc}
0,9 & 1 & -1 & -2 & 2 \\
1 & 1,9 & 1 & -2 & 3 \\
-1 & 1 & 5,9 & 3 & 1 \\
-2 & -2 & 3 & 5,9 & -4 \\
2 & 3 & 1 & -4 & 6,9
\end{array}\right]
\end{aligned}
$$

3. Perhitungan dengan metode kuasa invers dengan shift dengan memberikan nilai shift-nya yaitu

$$
\begin{aligned}
& (A-s I)=L U \\
& (A-S I)=L U \\
& {\left[\begin{array}{ccccc}
0,9 & 1 & -1 & -2 & 2 \\
1 & 1,9 & 1 & -2 & 3 \\
-1 & 1 & 5,9 & 3 & 1 \\
-2 & -2 & 3 & 5,9 & -4 \\
2 & 3 & 1 & -4 & 6,9
\end{array}\right]=} \\
& {\left[\begin{array}{cccccc}
1 & 0 & 0 & 0 & 0 \\
1,1111 & 1 & 0 & 0 & 0 \\
-1,1111 & 2,6761 & 1 & 0 & 0 \\
-2,2222 & 0,2817 & -0,2128 & 1 & 0 \\
2,2222 & 0,9859 & -1,3257 & 0,3269 & 1
\end{array}\right]}
\end{aligned}
$$




$$
\left[\begin{array}{ccccc}
0,9 & 1 & -1 & -2 & 2 \\
0 & 0,7889 & 2,1111 & 0,2222 & 0,7778 \\
0 & 0 & -0,8606 & 0,1831 & 1,1408 \\
0 & 0 & 0 & 1,4319 & 0,4681 \\
0 & 0 & 0 & 0 & 3,0481
\end{array}\right]
$$

4. Menyelesaikan $L Y=X_{0}$ $L Y=X_{0}$

$$
\begin{aligned}
& {\left[\begin{array}{ccccc}
1 & 0 & 0 & 0 & 0 \\
1,1111 & 1 & 0 & 0 & 0 \\
-1,1111 & 2,6761 & 1 & 0 & 0 \\
-2,2222 & 0,2817 & -0,2128 & 1 & 0 \\
2,2222 & 0,9859 & -1,3257 & 0,3269 & 1
\end{array}\right]\left[\begin{array}{l}
Y_{1} \\
Y_{2} \\
Y_{3} \\
Y_{4} \\
Y_{5}
\end{array}\right]=\left[\begin{array}{l}
-0,4772 \\
-0,4772 \\
-0,4772 \\
-0,4772 \\
-0,4772
\end{array}\right]} \\
& {\left[\begin{array}{l}
Y_{1} \\
Y_{2} \\
Y_{3} \\
Y_{4} \\
Y_{5}
\end{array}\right]=\left[\begin{array}{c}
-0,4772 \\
0,0530 \\
-1,1493 \\
-1,7971 \\
-0,4052
\end{array}\right]}
\end{aligned}
$$

5. Menyelesaikan $U Z=Y$

$$
U Z_{1}=Y
$$

$$
\begin{gathered}
{\left[\begin{array}{ccccc}
0,9 & 1 & -1 & -2 & 2 \\
0 & 0,7889 & 2,1111 & 0,2222 & 0,7778 \\
0 & 0 & -0,8606 & 0,1831 & 1,1408 \\
0 & 0 & 0 & 1,4319 & 0,4681 \\
0 & 0 & 0 & 0 & 3,0481
\end{array}\right]\left[\begin{array}{l}
Z_{1} \\
Z_{2} \\
Z_{3} \\
Z_{4} \\
Z_{5}
\end{array}\right]=\left[\begin{array}{c}
-0,4772 \\
0,0530 \\
-1,1493 \\
-1,7971 \\
-0,4052
\end{array}\right]} \\
{\left[\begin{array}{l}
Z_{1} \\
Z_{2} \\
Z_{3} \\
Z_{4} \\
Z_{5}
\end{array}\right]=\left[\begin{array}{c}
0,1555 \\
-1,8730 \\
0,9015 \\
-1,2116 \\
-0,1329
\end{array}\right]}
\end{gathered}
$$

6. Menghitung $Z_{1}$ dengan menormalisasikannya

$$
\begin{aligned}
Z_{1} & =\frac{Z}{\|Z\|} \\
= & {\left[\begin{array}{c}
0,0644 \\
-0,7757 \\
0,3734 \\
-0,5018 \\
-0,0551
\end{array}\right] }
\end{aligned}
$$

7. Mengalikan matriks $A$ dengan $Z_{1}$

$$
\begin{aligned}
A Z_{1} & =\left[\begin{array}{ccccc}
1 & 1 & -1 & -2 & 2 \\
1 & 2 & 1 & -2 & 3 \\
-1 & 1 & 6 & 3 & 1 \\
-2 & -2 & 3 & 6 & -4 \\
2 & 3 & 1 & -4 & 7
\end{array}\right]\left[\begin{array}{c}
0,0644 \\
-0,7757 \\
0,3734 \\
-0,5018 \\
-0,0551
\end{array}\right] \\
& =\left[\begin{array}{l}
-0,1912 \\
-0,2752 \\
-0,1603 \\
-0,2478 \\
-0,2031
\end{array}\right]
\end{aligned}
$$

8. Menghitung nilai eigen tak dominan menggunakan Kuosien Rayleigh

$$
\lambda_{1}=\frac{\left\langle Z_{1}, A Z_{1}\right\rangle}{\left\langle Z_{1}, Z_{1}\right\rangle}=0,2768
$$

Langkah selanjutnya $X_{0}=Z_{1}$, untuk menyelesaikan $L Y=X_{0}$

$$
L Y=X_{0}
$$




$$
\left[\begin{array}{ccccc}
1 & 0 & 0 & 0 & 0 \\
1,1111 & 1 & 0 & 0 & 0 \\
-1,1111 & 2,6761 & 1 & 0 & 0 \\
-2,2222 & 0,2817 & -0,2128 & 1 & 0 \\
2,2222 & 0,9859 & -1,3257 & 0,3269 & 1
\end{array}\right]\left[\begin{array}{c}
Y_{1} \\
Y_{2} \\
Y_{3} \\
Y_{4} \\
Y_{5}
\end{array}\right]=\left[\begin{array}{c}
0,0644 \\
-0,7757 \\
0,3734 \\
-0,5018 \\
-0,0551
\end{array}\right]
$$

Dan diperoleh $Y_{1}=0,0644 Y_{2}=-0,8473 Y_{3}=2,7123 Y_{4}=0,4571 \quad Y_{5}=4,0833$. Penyelesaian $U Z=Y$

$$
U Z_{1}=Y
$$

$$
\left[\begin{array}{ccccc}
0,9 & 1 & -1 & -2 & 2 \\
0 & 0,7889 & 2,1111 & 0,2222 & 0,7778 \\
0 & 0 & -0,8606 & 0,1831 & 1,1408 \\
0 & 0 & 0 & 1,4319 & 0,4681 \\
0 & 0 & 0 & 0 & 3,0481
\end{array}\right]\left[\begin{array}{l}
Z_{1} \\
Z_{2} \\
Z_{3} \\
Z_{4} \\
Z_{5}
\end{array}\right]=\left[\begin{array}{c}
0,0644 \\
-0,8473 \\
2,7123 \\
0,4571 \\
4,0833
\end{array}\right]
$$

Menghasilkan $Z_{1}=-6,2682 Z_{2}=1,3880 Z_{3}=-1,4011 Z_{4}=-0,1187 Z_{5}=1,3396$ Sehingga

Dengan mengalikan $Z_{2}$ dengan $A$ diperoleh

$$
Z_{2}=\left[\begin{array}{c}
-0,9345 \\
0,2069 \\
-0,2089 \\
-0,0177 \\
0,1997
\end{array}\right]
$$

$$
\begin{aligned}
A Z_{2} & =\left[\begin{array}{ccccc}
1 & 1 & -1 & -2 & 2 \\
1 & 2 & 1 & -2 & 3 \\
-1 & 1 & 6 & 3 & 1 \\
-2 & -2 & 3 & 6 & -4 \\
2 & 3 & 1 & -4 & 7
\end{array}\right]\left[\begin{array}{c}
-0,9345 \\
0,2069 \\
-0,2089 \\
-0,0177 \\
0,1997
\end{array}\right] \\
& =\left[\begin{array}{c}
-0,0839 \\
-0,0950 \\
0,0348 \\
-0,0766 \\
0,0118
\end{array}\right]
\end{aligned}
$$

Dan kuosien rayleigh perkiraan dari nilai eigen tak dominan adalah

$$
\lambda_{2}=\frac{\left\langle Z_{2}, A Z_{2}\right\rangle}{\left\langle Z_{2}, Z_{2}\right\rangle}=0,0551
$$

Kemudian dilakukan perhitungan dengan cara yang sama seperti di atas hingga iterasi ke -6 , karena $\lambda_{6}=\lambda_{5}$ yaitu nilai eigen tak dominan nya adalah $\lambda_{6}=\lambda_{5}$. Maka iterasi dihentikan.

\section{Matriks $5 \times 5$ Indefinit}

Diberikan sebarang matriks indefinit $5 \times 5$.

$$
A=\left[\begin{array}{ccccc}
1 & 2 & 1 & 1 & 1 \\
2 & 2 & 1 & 1 & 1 \\
1 & 1 & -2 & 1 & 1 \\
1 & 1 & 1 & 1 & 2 \\
1 & 1 & 1 & 2 & -1
\end{array}\right]
$$

Dengan vektor hampiran awal $\left[\begin{array}{l}-1 \\ -1 \\ -1 \\ -1 \\ -1\end{array}\right]$

Dengan menggunakan metode kuasa invers dengan shift untuk menentukan nilai eigen tak dominan dai matriks A

1. Nomalisasi vektor hampiran awal menghasilkan 


$$
X_{0}=\frac{1}{\sqrt{5}}\left[\begin{array}{l}
-1 \\
-1 \\
-1 \\
-1
\end{array}\right]=\left[\begin{array}{l}
-0,4772 \\
-0,4772 \\
-0,4772 \\
-0,4772 \\
-0,4772
\end{array}\right]
$$

2. Selanjutnya menentukan vektor eigen tak dominan dan nilai eigen tak dominan menggunakan metode kuasa invers dengan shift matriks A adalah menentukan nilai shift, matriks L dan matriks U. Menurut Teorema Gerschgorin daerah nilai eigen matriks A adalah

$$
\begin{aligned}
& |\lambda-1| \leq|2|+|1|+|1|+|1|=5 \\
& |\lambda-2| \leq|2|+|1|+|1|+|1|=5 \\
& |\lambda+2| \leq|1|+|1|+|1|+|1|=4 \\
& |\lambda-1| \leq|1|+|1|+|1|+|2|=5 \\
& |\lambda+1| \leq|1|+|1|+|1|+|2|=5 \\
& |\lambda-1| \leq 5 \Leftrightarrow-5<\lambda-1<5 \\
& \Leftrightarrow-5+1<\lambda<5+1 \\
& \Leftrightarrow-4<\lambda<6 \\
& |\lambda-2| \leq 5 \Leftrightarrow-5<\lambda-2<5 \\
& \Leftrightarrow-5+2<\lambda<5+2 \\
& \Leftrightarrow-3<\lambda<7 \\
& |\lambda-(-2)| \leq 4 \Leftrightarrow-4<\lambda+2<4 \\
& \Leftrightarrow-4-2<\lambda<4-2 \\
& \Leftrightarrow-6<\lambda<2 \\
& |\lambda-1| \leq 5 \Leftrightarrow-5<\lambda-1<5 \\
& \Leftrightarrow-5+1<\lambda<5+1 \\
& \Leftrightarrow-4<\lambda<6 \\
& |\lambda-(-1)| \leq 5 \Leftrightarrow-5<\lambda+1<5 \\
& \Leftrightarrow-5-1<\lambda<5-1 \\
& \Leftrightarrow-6<\lambda<4
\end{aligned}
$$

Jadi daerah nilai eigennya $-3<\lambda<2$. Dimisalkan diambil nilai shift $s=-0,2$ maka $A$ menjadi:

$$
\begin{aligned}
(A-s I) & =\left[\begin{array}{ccccc}
1 & 2 & 1 & 1 & 1 \\
2 & 2 & 1 & 1 & 1 \\
1 & 1 & -2 & 1 & 1 \\
1 & 1 & 1 & 1 & 2 \\
1 & 1 & 1 & 2 & -1
\end{array}\right]-\left[\begin{array}{ccccc}
-0,5 & 0 & 0 & 0 & 0 \\
0 & -0,5 & 0 & 0 & 0 \\
0 & 0 & -0,5 & 0 & 0 \\
0 & 0 & 0 & -0,5 & 0 \\
0 & 0 & 0 & 0 & -0,5
\end{array}\right] \\
& =\left[\begin{array}{ccccc}
1,5 & 2 & 1 & 1 & 1 \\
2 & 2,5 & 1 & 1 & 1 \\
1 & 1 & -1,5 & 1 & 1 \\
1 & 1 & 1 & 1,5 & 2 \\
1 & 1 & 1 & 2 & -0,5
\end{array}\right]
\end{aligned}
$$

3. Perhitungan dengan metode kuasa invers dengan shift dengan memberikan nilai shift-nya yaitu

$$
\begin{aligned}
& (A-s I)=L U \\
& (A-s I)=L U \\
& {\left[\begin{array}{cccccc}
1,5 & 2 & 1 & 1 & 1 \\
2 & 2,5 & 1 & 1 & 1 \\
1 & 1 & -1,5 & 1 & 1 \\
1 & 1 & 1 & 1,5 & 2 \\
1 & 1 & & 1 & 2 & -0,5
\end{array}\right]=} \\
& {\left[\begin{array}{ccccccc}
1 & 0 & 0 & 0 & 0 \\
1,3333 & 1 & 0 & 0 & 0 \\
0,6667 & 2 & 1 & 0 & 0 \\
0,6667 & 2 & -0,6667 & 1 & 0 \\
0,6667 & 2 & -0,6667 & 1,2308 & 1
\end{array}\right]} \\
& {\left[\begin{array}{llllcc}
1,5 & 2 & 1 & 1 & 1 \\
0 & -0,1667 & -0,3333 & -0,3333 & -0,3333 \\
0 & 0 & -1,5 & 1 & 1 \\
0 & 0 & 0 & 2,1667 & 2,6667 \\
0 & 0 & 0 & 0 & -3,1154
\end{array}\right]}
\end{aligned}
$$


4. Menyelesaikan $L Y=X_{0}$ $L Y=X_{0}$

$\left[\begin{array}{cccc}1 & 0 & 0 & 0 \\ 1,3333 & 1 & 0 & 0 \\ 0,6667 & 2 & 1 & 0 \\ 0,6667 & 2 & -0,6667 & 1 \\ 0,6667 & 2 & -0,6667 & 1,2308\end{array}\right.$

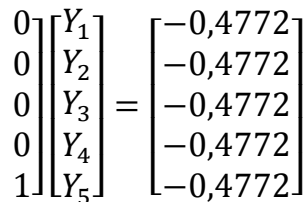

5. Menyelesaikan $U Z=Y$

$$
\left[\begin{array}{l}
Y_{1} \\
Y_{2} \\
Y_{3} \\
Y_{4} \\
Y_{5}
\end{array}\right]=\left[\begin{array}{c}
-0,4772 \\
0,1591 \\
-0,4772 \\
-0,7953 \\
0,1835
\end{array}\right]
$$

$U Z_{1}=Y$

$$
\begin{array}{r}
{\left[\begin{array}{ccccc}
1,5 & 2 & 1 & 1 & 1 \\
0 & -0,1667 & -0,3333 & -0,3333 & -0,3333 \\
0 & 0 & -1,5 & 1 & 1 \\
0 & 0 & 0 & 2,1667 & 2,6667 \\
0 & 0 & 0 & 0 & -3,1154
\end{array}\right]\left[\begin{array}{l}
Z_{1} \\
Z_{2} \\
Z_{3} \\
Z_{4} \\
Z_{5}
\end{array}\right]=\left[\begin{array}{c}
-0,4772 \\
0,1591 \\
-0,4772 \\
-0,7953 \\
0,1835
\end{array}\right]} \\
{\left[\begin{array}{l}
Z_{1} \\
Z_{2} \\
Z_{3} \\
Z_{4} \\
Z_{5}
\end{array}\right]=\left[\begin{array}{c}
0,4124 \\
-0,4124 \\
0,0825 \\
-0,2946 \\
-0,0589
\end{array}\right]}
\end{array}
$$

6. Menghitung $Z_{1}$ dengan menormalisasikannya

$$
\begin{aligned}
Z_{1} & =\frac{Z}{\|Z\|} \\
& =\left[\begin{array}{c}
0,6237 \\
-0,6237 \\
0,1247 \\
-0,4455 \\
-0,0891
\end{array}\right]
\end{aligned}
$$

7. Mengalikan matriks $A$ dengan $Z_{1}$

$$
\begin{aligned}
A Z_{1} & =\left[\begin{array}{ccccc}
1 & 2 & 1 & 1 & 1 \\
2 & 2 & 1 & 1 & 1 \\
1 & 1 & -2 & 1 & 1 \\
1 & 1 & 1 & 1 & 2 \\
1 & 1 & 1 & 2 & -1
\end{array}\right]\left[\begin{array}{c}
0,6237 \\
-0,6237 \\
0,1247 \\
-0,4455 \\
-0,0891
\end{array}\right] \\
& =\left[\begin{array}{l}
-1,0336 \\
-0,4099 \\
-0,7841 \\
-0,4990 \\
-0,6772
\end{array}\right]
\end{aligned}
$$

8. Menghitung nilai eigen tak dominan menggunakan Kuosien Rayleigh

$$
\lambda_{1}=\frac{\left\langle Z_{1}, A Z_{1}\right\rangle}{\left\langle Z_{1}, Z_{1}\right\rangle}=-0,2042
$$

Langkah selanjutnya $X_{0}=Z_{1}$, untuk menyelesaikan $L Y=X_{0}$

$$
L Y=X_{0}
$$

$$
\left[\begin{array}{ccccc}
1 & 0 & 0 & 0 & 0 \\
1,3333 & 1 & 0 & 0 & 0 \\
0,6667 & 2 & 1 & 0 & 0 \\
0,6667 & 2 & -0,6667 & 1 & 0 \\
0,6667 & 2 & -0,6667 & 1,2308 & 1
\end{array}\right]\left[\begin{array}{l}
Y_{1} \\
Y_{2} \\
Y_{3} \\
Y_{4} \\
Y_{5}
\end{array}\right]=\left[\begin{array}{c}
0,6237 \\
-0,6237 \\
0,1247 \\
-0,4455 \\
-0,0891
\end{array}\right]
$$


Dan diperoleh $Y_{1}=0,6237 Y_{2}=-1,4553 Y_{3}=2,6195 Y_{4}=3,7956 \quad Y_{5}=-0,5195$. Penyelesaian $U Z=Y$

$$
U Z_{1}=Y
$$

$$
\left[\begin{array}{ccccc}
1,5 & 2 & 1 & 1 & 1 \\
0 & -0,1667 & -0,3333 & -0,3333 & -0,3333 \\
0 & 0 & -1,5 & 1 & 1 \\
0 & 0 & 0 & 2,1667 & 2,6667 \\
0 & 0 & 0 & 0 & -3,1154
\end{array}\right]\left[\begin{array}{l}
Z_{1} \\
Z_{2} \\
Z_{3} \\
Z_{4} \\
Z_{5}
\end{array}\right]=\left[\begin{array}{c}
0,6237 \\
-1,4553 \\
2,6195 \\
3,7956 \\
-0,5195
\end{array}\right]
$$

Menghasilkan $Z_{1}=-9,0081 Z_{2}=6,5133 Z_{3}=-0,6041 Z_{4}=1,5466 Z_{5}=0,1668$ Sehingga

Dengan mengalikan $Z_{2}$ dengan $A$ diperoleh

$$
Z_{2}=\left[\begin{array}{c}
-0,8014 \\
0,5794 \\
-0,0537 \\
0,1376 \\
0,0148
\end{array}\right]
$$

$$
A Z_{1}=\left[\begin{array}{ccccc}
1 & 2 & 1 & 1 & 1 \\
2 & 2 & 1 & 1 & 1 \\
1 & 1 & -2 & 1 & 1 \\
1 & 1 & 1 & 1 & 2 \\
1 & 1 & 1 & 2 & -1
\end{array}\right]\left[\begin{array}{c}
-0,8014 \\
0,5794 \\
-0,0537 \\
0,1376 \\
0,0148
\end{array}\right]
$$

$$
=\left[\begin{array}{c}
0,4562 \\
-0,3452 \\
0,0380 \\
-0,1084 \\
-0,0153
\end{array}\right]
$$

Dan kuosien rayleigh perkiraan dari nilai eigen tak dominan adalah

$$
\lambda_{2}=\frac{\left\langle Z_{2}, A Z_{2}\right\rangle}{\left\langle Z_{2}, Z_{2}\right\rangle}=-0,5828
$$

Kemudian dilakukan perhitungan dengan cara yang sama seperti di atas hingga iterasi ke -3, Jadi nilai eigen tak dominan matriks $5 \times 5$ indefinit adalah $-0,5828$. Penentuan nilai eigen tak dominan menggunakan metode kuasa invers dengan shift berhenti pada iterasi ke 2 , karena $\lambda_{3}=\lambda_{2}$.

\section{Kesimpulan}

Berdasarkan pembahasan yang dilakukan maka dapat disimpulkan sebagai berikut :

1. Selain berlaku untuk matriks simetrik definit positif dan negatif, Penentuan nilai eigen tak dominan berlaku juga pada matriks simetrik semi definit positif, semi definit negatif, dan indefinit.

2. Nilai eigen tak dominan pada matriks $5 \times 5$ semi definit positif dan semi definit negatif adalah 0,0000 . Iterasi berhenti pada iterasi ke-6.

3. Nilai eigen tak dominan pada matriks $5 \times 5$ indefinit adalah $-0,5828$. Iterasi berhenti pada iterasi ke-3 4. Nilai shift sangat berpengaruh terhadap iterasi yang akan dilakukan. Semakin nilai shift mendekati nilai eigen tak dominan, maka semakin sedikit iterasi yang akan dilakukan. Jadi penggunaan metode kuasa invers dengan shift akan lebih baik jika nilai shift yang diperkirakan sangat mendekati nilai eigen tak dominan. 


\section{Daftar Pustaka}

[1] Andriani, Yuli. 2011. "Menentukan Nilai Eigen Tak Dominan Suatu Matriks Definit Negatif Menggunakan Metode Kuasa Invers dengan Shift". Jurnal Penelitian Sains. Vol. 14 No. 1(A).

[2] Anggraini, Wiwik. 2006. Aljabar Linear dengan Matlab. Edisi Pertama. Jakarta: Erlangga.

[3] Anton, Howard. 1987. Aljabar Linear Elementer. Edisi Kelima. Jakarta: Erlangga.

[4] Anton, Howard, Chris Rorres. 2005. Aljabar Linear Elementer versi Aplikasi. Edisi Kedelapan/Jilid 2. Jakarta: Erlangga.

[5] Anton, Howard, Chris Rorres. 2005. Elementary Linear Algebra Applications Version. Ninth Edition. John Wiley \& Sons, Inc.

[6] Anton, Howard, Chris Rorres. 2010. Elementary Linear Algebra Applications Version. Tenth Edition. John Wiley \& Sons, Inc.

[7] Leon, Steven J. 2001. Aljabar Linear dan Aplikasinya. Edisi Kelima. Jakarta: Erlangga.

[8] Serre, Denis. 2010. Matrices Theory and Applications. Second Edition. Springer. 